\title{
ПРЕЗИДЕНТСКИЕ ВЫБОРЫ В СЛОВАКИИ 2019 ГОДА КАК КРИЗИС ДОВЕРИЯ ВЛАСТИ ${ }^{1}$
}

\begin{abstract}
Аннотация. В марте 2019 г. в Словакии прошли выборы президента страны. Для его определения потребовались два тура, в ходе которых убедительную победу дважды одержала адвокат-правозащитник Зюзана Чапутова, которая ранее активно не участвовала в политической жизни страны. Несмотря на представительско-церемониальные функиии главы государства в парламентской республике, каковой является Словакия, данная избирательная кампания показала запрос населения на новых политиков, не связанных с истеблишментом, в особенности с представителями правящей партии СМЕР - Социальная демократия.

Ключевые слова: Словакия, Роберт Фиио, Марош Шефчович, Зюзана Чапутова, СМЕР Социальная демократия, выборы президента.
\end{abstract}

16 марта 2019 г. в Словакии состоялся первый тур президентских выборов, в ходе которого не удалось определить победителя, что привело к необходимости проведения 30 марта второго этапа народного волеизъявления. В н`м участвовали два кандидата, набравшие наибольшее количество голосов избирателей, а именно Зюзана Чапутова (40,57\%), выдвинутая партией Прогрессивная Словакия, и Марош Шефчович (18,66\%), независимый кандидат, поддержанный 47-ю подписями депутатов правящей партии СМЕР - Социальная демократия (СМЕР-СД). По итогам заключительного тура ожидаемую победу праздновала 3. Чапутова, которая получила $58,41 \%$, её соперник $-41,59 \%$. Явка составила $41,79 \%{ }^{2}$.

Изначально в президентской гонке участвовали 17 кандидатов, однако по ходу её развития их количество сократилось на две позиции. В начале февраля от участия отказался председатель Партии венгерского общества (Strany mad'arskej komunity) Йозеф Менхарт. Спустя несколько недель о самоотводе в пользу 3. Чапутовой заявил один из потенциальных кандидатов на успех Роберт Мистрик, занимавший на тот момент третье место, согласно данным соцопросов.

Важно отметить, что одной из особенностей электорального цикла стало то, что партия СМЕР-СД на протяжении долгого времени не могла определиться со своим кандидатом. Изначально от участия отказался её председатель Роберт Фицо, скорее всего из-за нежелания повторять печальный опыт пятилетней давности, когда он проиграл нынешнему президенту Андрею Киске, а также ввиду политического кризиса, разразившегося в 2018 г. В ходе этого кризиса под давлением общественного мнения и массовых демонстраций он был вынужден покинуть пост премьер-министра страны. Осознавая свои малые шансы на успех и понимая важность проведения успешной кампании, которая бы прервала череду неудачных муници-

(C) Ведерников Михаил Владимирович - кандидат исторических наук, старший научный сотрудник Центра Вишеградских исследований Отдела исследований Центральной и Восточной Европы ИЕ РАН. Адрес: 125009, Россия, Москва, ул. Моховая, д. 11. E-mail: vishma@ mail.ru.

DOI: http://dx.doi.org/10.15211/vestnikieran220195965

${ }^{1}$ Сокращённый вариант статьи был опубликован на сайте «Российского совета по международным делам». См.: https://russiancouncil.ru/analytics-and-comments/analytics/novoe-progressivnoe-litso-slovakii/

${ }^{2}$ Výsledky prezidentských volieb 2019 - 2.kolo. URL: https://volby.sme.sk/prezidentske-volby/2019/vysledky. 
пальных выборов в 2017-2018 гг., на которых представители СМЕР-СД теряли занятые в предшествующее время позиции ${ }^{1}$, руководство партии старалось выдвинуть в качестве кандидата на пост президента страны министра иностранных дел Мирослава Лайчака, одного из самых известных словаков современности. В 2017 г. он был избран Председателем 72-й Генеральной Ассамблеи ООН. В свою очередь, тот отказался от такого предложения, объяснив это желанием продолжать работать на дипломатической службе.

В такой ситуации необходимо было предложить конкурентоспособного политика, который смог бы побороться за пост главы государства. Выбор остановился на Мароше Шефчовиче, профессиональном дипломате, заместителе председателя Европейской комиссии Ж.-К. Юнкера и европейском комиссаре по вопросам энергетики. Его профессиональный опыт, широкий круг знакомств в высших органах власти Европейского союза должны были стать теми преимущественными качествами, которые бы привлекали потенциальных избирателей. Неудивительно, что одним из самых распространённых лозунгов М. Шефчовича стали следующие слова: «Сильная Словакия нуждается в опытном президенте, а не в новичке». Тем самым делалась отсылка к ближайшим конкурентам, а именно Чапутовой и Мистрику, для которых деятельность на политическом поприще была новой сферой применения своих талантов, поскольку первая была адвокатом-правозащитником, а второй - учёным-химиком.

Вплоть до 26 февраля потенциальные шансы на выход во второй тур имели четыре кандидата, к которым помимо уже обозначенных можно было отнести Штефана Гарабина, бывшего министра юстиции Словакии. Он сплотил вокруг себя определённую прослойку избирателей, с одной стороны, недовольных политическим курсом нынешнего правительства во главе с СМЕР-СД, а с другой, противников еврооптимистической риторики Шефчовича, Чапутовой и Мистрика. Как отмечают политологи, в данной ситуации мог сложиться такой расклад, в котором бы оба либеральных кандидата, выступавших против «людей прошлого и политических бизнесменов» из СМЕР-СД, остались бы за пределами борьбы в рамках решающего тура. В данных обстоятельствах между 3. Чапутовой и Р. Мистриком было заключён негласный договор, согласно которому последний отказывался от участия в выборах в её пользу. Можно говорить, что подобный гамбит полностью перевернул игру, поставив Шефчовича в неудобное положение, когда преимущество его главного конкурента стало исчисляться уже не однозначным показателем, а двузначным. Так, если до 26 февраля, согласно данным соцопросов, 3. Чапутову были готовы поддержать $23,5 \%$ респондентов, М. Шефчовича - 20,5\%, Р. Мистрика $-15 \%$, Ш. Гарабина $-10 \%$, то уже на момент последнего официально разрешённого исследования общественного мнения $\left(1\right.$ марта) ${ }^{3}$ показатели выглядели следующим образом: 3. Чапутова $-52,9 \%$, М. Шефчович $-16,7 \%$, Ш. Гарабин $-11,4 \%{ }^{4}$.

Если изначально 3. Чапутова вступила в борьбу за президентское кресло, как представитель исключительно партии «Прогрессивная Словакия», то после совершённой рокировки она заручилась поддержкой других политических сил, которые увидели в ней кандидата от оппозиции, имеющего все шансы добиться победы в сражении с правящей СМЕР-СД. Так, поддержку ей высказали партии «Вместе - гражданская демократия» (SPOLU - občianska demokracia), «Свобода и солидарность» (Sloboda a Solidarita) и «Обычные люди и независимые лично-

\footnotetext{
${ }^{1}$ Марушьяк Ю. Кризис поддержки партии Смер - Социальная демократия в 2017-2018 гг. Современная Европа. №7, 2018. C. 73-74.

2 V novom prezidentskom prieskume už vedie Čaputová pred Šefčovičom URL: https://www.aktuality.sk/clanok/ 670668/v-novom-prezidentskom-prieskume-uz-vedie-caputova-pred-sefcovicom/

${ }^{3}$ Согласно словацкому законодательству публикация данных соцопросов прекращается за две недели до выборов. Сделано это с целью не оказывать влияние на решение избирателей.

4 Posledný prieskum pred vol'bami: Čaputová vyletela nad 50 percent. URL: https://www.aktuality.sk/clanok/ 671595/posledny-prieskum-pred-volbami-caputova-vyletela-nad-50-percent/
}

Научно-аналитический вестник ИЕ РАН, 2019, №2 
сти (Obyčajní L'udia a nezávislé osobnosti) ${ }^{1}$. Более того, ей выразил поддержку беспартийный президент страны Андрей Киска. Подобный шаг главы государства, который должен был бы демонстрировать своё положение над схваткой и не вмешиваться в предвыборные баталии, вызвал недовольство со стороны Шефчовича, который заподозрил его в сговоре с Чапутововой. Подобная сделка, по мнению кандидата, была необходима президенту после сложения с него полномочий, поскольку в его отношении предстояло уголовное расследование касательно денежных махинаций, в которых он якобы был замечен. Несмотря на опровержение этих заявлений со стороны как Чапутовой, так и Киски, который заявил, что «не нуждается в помиловании», ситуация продемонстрировала высокий градус напряжения президентской гонки. В ход пошли прямые обвинения, выходящие за рамки обычной политической дискуссии. Обсуждению вновь подверглось сделанное в 2017 г. заявление президента о «мафиозной» сущности словацкого государства, проникновении преступных связей в высшие эшелоны власти ${ }^{2}$. В такой ситуации, подрывающей авторитет не только кандидата правящей партии, но и самого правительства, выступил его глава Петер Пеллегрини, второй человек в СМЕР-СД. Он заявил, что «не хочет, чтобы новый президент учился новым вещам, как это было в случае с Киской», называя при этом Чапутову - «неизвестной девушкой, мотающейся по свалкам» 3 .

Таким образом, можно говорить, что в последние три недели перед выборами основная борьба развернулась между двумя кандидатами, которые, с одной стороны, являлись представителями разных политических групп, но, с другой, были носителями одинаковых идеологических и мировоззренческих установок. Так, во время заключительных теледебатов на канале TV Markiza Ш. Гарабин назвал их «сиамскими близнецами», что во многом подтверждается, если посмотреть на анкету-опросник, которую заполняли кандидаты в президенты по просьбе информационного агентства Aktuality.sk. На вопрос об их отношении к ЕС и НАТО М. Шефчович ответил, что «это наше естественное пространство, которое способствует развитию Словакии»; 3. Чапутова, что «ЕС и НАТО являются главными столпами нашей внешней политики». Относительно миграции оба кандидата сходились во мнении о необходимости поиска прагматичных решений в рамках Европейского союза и укрепления внешних границ. Свою цель на посту президента они видели в проведении официального курса внешней политики страны для укрепления положения Словакии в рамках ЕС и НАТО.

В свою очередь их ближайшие конкуренты Ш. Гарабин и М. Котлеба, глава партии Народная партия - Наша Словакия, имели альтернативное видение озвученных проблем. Последний высказал инициативу проведения референдума о выходе страны из ЕС и НАТО. Он объяснял это тем, что скорейшее осуществление такого плана приведёт к исключению возможности втягивания Словакии в конфликт с Россией. Гарабин в этом вопросе указывал на необходимость вернуться к первоначальному замыслу Европейского союза, который сводился исключительно к экономическому сотрудничеству государств без ограничения национального суверенитета. В миграционном вопросе оба политика сходились во мнении, что первоначально надо было избавиться от затруднений внутри собственной страны, а уже потом решать проблемы других людей.

Ввиду того, что многие вопросы, которые поднимались в ходе предвыборной кампании, е входят в список полномочий президента парламентской республики, каковой является Словакия (например, разработка внешней политики, формулирование политической повестки), кандидаты были вынуждены обозначить свою уникальность и отличие от конкурента поиском

\footnotetext{
${ }_{1}^{1}$ После победы в первом туре поддержку выразила также и партия Мост-Хид, участник правящей коалиции.

${ }^{2}$ URL: https://dennikn.sk/1405896/je-slovensko-mafiansky-stat-ako-to-hovori-kiska-prezidentska-anketa/

${ }^{3}$ В 2013 г. она была лидером общественной кампании против размещения незаконной мусорной свалки вблизи г. Пезинок.
}

Научно-аналитический вестник ИЕ РАН, 2019, №2 
собственных приоритетных тем. Так, М. Шефчович во многом следовал риторике СМЕР-СД, уделяя внимание вопросам социального обеспечения и создания социального государства. Использование программы правящей партии для привлечения преданной ей аудитории привело к тому, что к концу избирательного цикла некоторые политологи отметили, что некогда независимый кандидат полностью проникся присущей СМЕР идеологией. Они также отмечали, что использованная тактика во многом соответствовала той, к которой прибегал сам лидер партии Р. Фицо пять лет назад и которая не принесла ему успеха.

В последнюю неделю перед первым туром, когда данные соцопросов показывали возрастающую популярность конкурентов М. Шефчовича, имевших возможность исключить его из борьбы во втором туре, он скорректировал шаги ${ }^{1}$. Это выразилось в активизации взаимодействия с консервативной аудиторией, потенциальными сторонниками Ш. Гарабина и отчасти М. Котлебы. Для этого в его выступлениях начала отчётливо звучать тема, касающаяся его глубокой приверженности к ценностям католической церкви, его контактов с Папой Римским Иоанном Павлом II. Были предприняты и активные действия в этом направлении. 7 марта состоялась встреча с представителями христианских церквей и религиозных организаций. Её центральной темой стала демонстрация кандидатом своей культурно-ценностной ориентации в области семейных отношений ${ }^{2}$. В то время как ближайший конкурент М. Шефчовича высказывалась за легализацию однополых браков и предоставление представителям ЛГБТК отсутствовавших у них прав, Шефчович заявил о необходимости следовать Конституции, где под браком подразумевался союз между мужчиной и женщиной; также он выступил против усыновления детей однополыми парами. Казалось бы, незначительный вопрос, касающийся частной жизни словаков, перерос в общенациональную дискуссию, в ходе которой некоторые церковные деятели заявили, что «поддержка либеральной кандидатки является грехом». Таким образом Шефчович планировал перетянуть на свою сторону как сторонников Гарабина и Котлебы, для которых их заявления по внешней политике казались слишком радикальными, так и от Чапутовой, которая обладала слишком либеральными и чересчур прогрессивными взглядами.

Для привлечения женской аудитории, симпатизировавшей 3. Чапутовой или ещё не определившейся в своём выборе, предвыборный штаб СМЕР-СД обратился к возможности использовать Международный женский день (8 марта), празднование которого проходило в непосредственной близости от дня проведения голосования. С этой целью в крупных словацких городах за несколько дней до и после праздника были проведены бесплатные концерты, на которых выступали артисты, танцоры и музыканты. В качестве обязательного дополнения проходили выступления Р. Фицо, П. Пеллегрини, которые между прочим агитировали голосовать за М. Шефчовича. В этой связи можно говорить об использовании феминистической тематики и попытке привлечь на сторону еврокомиссара женскую аудиторию, важность которой также определялась её численным перевесом по сравнению с мужской и большей избирательной активностью, показанной в предшествующие годы.

В то время как М. Шефчович предпринимал меры, чтобы остаться на плаву и выйти во второй тур, 3. Чапутова не отклонялась от выбранного ей курса. Прежде всего это выразилось в том, что её риторика на протяжении всей президентской кампании содержала представление о политической борьбе как сражении между добром и злом, правды и лжи, законности и беззакония и т.д., где положительными качествами обладала она и её сторонники, а негатив-

\footnotetext{
${ }^{1}$ В качестве примера вспоминали выборы президента 2004 г., в ходе которых во второй тур не прошёл Эдуард Кукан, который пропустил вперед ставшего затем президентом Ивана Гашпаровича.

Je Slovensko mafiánsky štát, ako to hovorí Kiska? (prezidentská anketa). URL: https://spravy.pravda.sk/domace/ clanok/504613-sefcovic-po-stretnuti-s-predstavitelmi-krestanskej-cirkvi-sme-nasli-velmi-dobre-hodnotove-prieniky/
}

Научно-аналитический вестник ИЕ РАН, 2019, №2 
ными - представители правящей партии. Использование подобных бинарных оппозиций, упрощавших само понимание политических процессов, низводя политиков на условно хороших и плохих, когда не происходило углубление в суть вопроса, вело к нагнетанию настроений. Вдобавок в обстановке, когда страна, начиная с 2018 г. находилась под сильным впечатлением от убийства журналиста Я. Куцияка, расследовавшего причастность правительственных кругов к мафиозной группировке «Ндрангетта», антиправительственные настроения только усиливались. Это не могло не вызвать протест со стороны либерально настроенных избирателей и тех, кто хотел обновления политической обстановки в Словакии.

Представление некоторых политологов о том, что выборы 2019 г. продемонстрировали состязание между консервативной и либеральной идеологиями, сложно считать правдоподобным. Прежде всего, маловероятным такое сравнение кажется относительно противостояния Чапутовой и Шефчовича, предшествовавшая деятельность которого, по словам некоторых комментаторов, была «связана пуповиной» с Брюсселем, где всегда превалировали ценности либеральной демократии. Таким образом, его поворот в сторону укрепления традиционных ценностей объясняется плановыми действиями в рамках кампании для привлечения целевой аудитории. Выбранная им модель поведения, с одной стороны, позволила не допустить проход во второй тур ни Ш. Гарабина, ни М. Котлебу, но, с другой, не дала возможности заручиться превалирующей поддержкой у электората, приверженного традиционным и консервативным ценностям. Отчётливо это видно на примере Прешовского края, где, несмотря на самые высокие показатели по стране, отданные в пользу Шефчовича $(20,15 \%)$, его преимущество в сравнении с Гарабиным составляло лишь 2\%; в остальных 7 краях разница между двумя кандидатами колебалась между 3 и 6,5\%. В то же время важно отметить, что везде на территории Словакии с завидным преимуществом победу праздновала 3. Чапутова, которой удалось даже преодолеть 50\%-ный барьер в Братиславском крае $(59,65 \%)$.

Второй тур президентских выборов - характерная черта словацкой политической традиции. В пятый раз, начиная с 1999 г., потребовалась дополнительная попытка для выявления победителя. Анализируя предшествующие кампании, можно говорить о том, что для них всегда (за исключением 2009 г.) было свойственно протестное голосование. Так, в 1999 г. оно прошло под знаком «демечиаризации» словацкой политики, ввиду провозглашённого курса нового правительства Микулаша Дзуринды на вступление страны в ЕС и в НАТО, что была невозможно при нахождении у власти Владимира Мечиара - противнике данных инициатив. В 2004 г. ситуация во многом повторилась, поскольку в итоговой схватке за пост президента столкнулись Мечиар и Иван Гашпарович, на тот момент член непарламентской партии «Движение за демократию». Персона бывшего одиозного премьер-министра, который вновь решил заявить о себе, сыграла в пользу до той поры не имевшего широкой поддержки Гашпаровича. Последний также одержал победу и спустя пять лет, в 2009 г.

Важно отметить парадокс, что в период с 1994 по 1998 гг. избранный президент был председателем парламента, т.е. был во многом ответственным за состояние словацкой политики при руководстве страной Мечиаром. Однако это не остановило избирателей отдать голос в его поддержку. В 2014 г. выборы снова носили протестный характер, направленный против лидера СМЕР-СД Роберта Фицо. Несмотря на успех партии в предшествовавших парламентских выборах в 2012 г., по итогам которых она получила больше половины мест в законодательном органе, успех праздновал независимый кандидат А. Киска, не получивший поддержку от основных оппозиционных сил ${ }^{1}$.

${ }^{1}$ Charvat J., Just P. Cesta k příme volbě prezidenta na Slovensku a v České republice. Politics in Central Europe 10 (2014) 2. P. 22-23.

Научно-аналитический вестник ИЕ РАН, 2019, №2 
Таким образом, можно говорить об определённой преемственности нынешних выборов, когда в схватке за пост главы государства сталкиваются две персоны, представляющие диаметрально противоположные лагери - политического истеблишмента и дебютантов (или «аутсайдеров») на политической сцене.

Второй тур стал продолжением намеченных ранее подходов в выстраивании президентской кампании как Чапутовой, так и Шефчовича. Последний, понимая важность привлечения консервативной аудитории, голосовавшей изначально за Гарабина и Котлебу, усилил свою риторику в их направлении. Вдобавок задача осложнилась тем, что эти бывшие кандидаты призвали своих симпатизантов не участвовать в выборах. Помимо постоянного противопоставления себя с либеральной кандидаткой в вопросах культурно-ценностной ориентации Шефчович заявлял о разном видении будущего Словакии в Евросоюзе, который он не позиционировал как «супергосударство», где происходит унификация стран. Он говорил о предоставлении им бо́льших возможностей для отстаивания национальных интересов, особенно в миграционном вопросе, в сфере налогообложения. Важным событием на пути подтверждения этого курса стала встреча с президентом Чехии Милошем Земаном, сторонником именно тех идей, которые продвигал словацкий кандидат в ходе своей кампании. Поддержка на междуна-родном уровне также должна была прибавить ему привлекательность в глазах избирателей.

Что занимательно, в тот же день, когда проходили переговоры между чешским и словацким политиками в Ланах, 3. Чапутова организовала встречу со своими сторонниками на горе Ситно, где, согласно народному преданию, спят словацкие рыцари, которые будут разбужены в трудный для страны час. Подобные исторические реминисценции позволили комментаторам провести очевидные параллели, где Чапутова спасала Словакию от «угрозы со стороны СМЕР-СД», и заговорить о выборах как о референдуме по вопросу поддержки правящей партии. Победа Чапутовой стала бы индикатором желания населения видеть иной вектор развития страны.

Конечно, предвыборная гонка не обошлась и без различных разоблачений, попыток уличить конкурента в совершении противоправных деяний. Так, Шефчович обвинил своего конкурента в том, что во время адвокатской практики она нарушала правила оказания услуг, предоставляя их за пределами своего округа. В свою очередь Чапутова обратила внимание на то, что её соперник в последние дни кампании получил большую денежную помощь в размере 230 тыс. евро от СМЕР-СД. Подобная диффамация вряд ли могла поколебать веру большей части избирателей в своих фаворитов, за исключением тех, кто в своём выборе не был полностью уверен. В этой связи продолжающееся расследование убийства журналиста Я. Куцияка, в котором по ходу кампании проявлялись новые неожиданные аспекты, касающиеся связи заказчика преступления Марианна Кочнера с чиновниками высшего эшелона, оказывали куда более существенное влияние на избирателей. Отождествляя Шефчовича с представителями официальной власти, они делали выбор не в его пользу.

Говоря об итогах, предсказуемых в контексте данных соцопросов, но в то же время неожиданных, наметить которые полтора месяца назад было невозможно, стоит подчеркнуть общий центральноевропейский тренд, связанный с демонстрацией предпочтений избирателей в сторону нетрадиционных партий, движений и независимых политических персоналий. Примером этому может служить Чехия, где население голосует в пользу новых, политически неангажированных сил («Пираты», до недавнего времени АНО во главе с А. Бабишем), несущих в себе альтернативное решение существующих проблем. Что касается Словакии, то череда внутриполитических кризисов, судебных разбирательств, в которых были замешаны предста-

Научно-аналитический вестник ИЕ РАН, 2019, №2 
вители власти, вдобавок с «еврооптимистическим» курсом страны, актуальность которого поддерживается большинством населения, не могли не привести к выдвижению на политическую сцену оппозиционного кандидата. Впрочем, пять лет назад ситуация во многом была схожей. Но в том случае не удалось развить успех в ходе последовавших парламентских выборов ввиду появления незапланированной повестки (а именно миграционного кризиса, напряжённых отношений с Евросоюзом), к которой правящая партия сумела более успешно подготовиться и предложить её решение. В нынешних обстоятельствах словацкие политологи заговорили о возможности формирования силы, способной объединить вокруг себя политически активных жителей страны и выступить на следующих крупных выборах в 2020 г. В свою очередь победившая 3. Чапутова могла бы стать олицетворением этого движения.

\section{Список литературы}

Charvat J., Just P. Cesta k příme volbě prezidenta na Slovensku a v České republice. Politics in Central Europe, №2, 2014. Р. 10.

Марушьяк Ю. Кризис поддержки партии Смер - Социальная демократия в 2017-2018 гг. Современная Европа, №7, 2018. С. 73-74.

Центральная Европа: политический портрет на фоне 100-летия. Под ред. Л.Н. Шишелиной, М.В. Ведерникова. М., ИЕ РАН, 2018.

\section{References}

Výsledky prezidentských volieb 2019 - 2. kolo. URL: https://volby.sme.sk/prezidentskevolby/2019/vysledky.

V novom prezidentskom prieskume už vedie Čaputová pred Šefčovičom URL: https://www.aktu ality.sk/clanok/670668/v-novom-prezidentskom-prieskume-uz-vedie-caputova-pred-sefcovicom/

Posledný prieskum pred vol'bami: Čaputová vyletela nad 50 percent. URL: https://www. aktuali ty.sk/clanok/671595/posledny-prieskum-pred-volbami-caputova-vyletela-nad-50-percent/

Je Slovensko mafiánsky štát, ako to hovorí Kiska? (prezidentská anketa). URL: https://spravy. pravda.sk/domace/clanok/504613-sefcovic-po-stretnuti-s-predstavitelmi-krestanskej-cirkvi-smenasli-velmi-dobre-hodnotove-prieniky/

\section{Presidential Elections in Slovakia 2019 as a Crisis of Trust to Authorities}

Author. Mikhail Vedernikov, Candidate of Sciences (History), Senior Research Associate, Department of Central and Eastern European Studies, Institute of Europe, Russian Academy of Sciences. Address: 11-3, Mokhovaya str., Moscow, Russia, 125009. E-mail: vishma@ @ail.ru.

Abstract. In March 2019 presidential elections were held in Slovak Republic. After two rounds Zuzana Čaputova, lawyer and human rights defender, had a convincing victory. It's worth mentioning that she had not actively participated in the political life before her campaign. Despite the representative functions of the head of the state in a parliamentary republic the elections showed a popular demand for new politicians who are not associated with the establishment, especially with the representatives of the ruling party SMER - Social Democracy.

Key words: Slovakia, Robert Fico, Maroš Šefčović, Zuzana Čaputova, SMER - Social democracy, presidential election.

DOI: http://dx.doi.org/10.15211/vestnikieran220195965 